Risk, Danger, and Trust

Refining the Relational Theory of Risk

Christoffersen, Mikkel Gabriel

Published in:

Journal of Risk Research

DOI:

https://dx.doi.org/10.1080/13669877.2017.1301538

Publication date:

2018

Citation for published version (APA):

Christoffersen, M. G. (2018). Risk, Danger, and Trust: Refining the Relational Theory of Risk. Journal of Risk Research, 21(10), 1233-1247. https://doi.org/10.1080/13669877.2017.1301538 


\title{
Risk, Danger, and Trust: Refining the Relational Theory of Risk Mikkel Gabriel Christoffersen
}

\begin{abstract}
The "relational theory of risk," proposed by Åsa Boholm and Hervé Corvellec in Journal of Risk Research (2011), offers a theory of human constructions of risk, a theory that has not only sociological but also ethical implications. Drawing upon interdisciplinary sociological and philosophical material, the present article suggests three ways to refine the relational theory of risk. First, I call attention to threatening relationships that are dangerous rather than risky. Second, I argue that a risk relationship only implies the "exclusion" of the threatening object if the person who constructs the risk relationship chooses to distrust the threatening object rather than to trust it. Third, I amend the relational theory's explanation of social risk conflicts by raising the question of the origin of the harm, either in the injured party itself or in the external environment. These refinements strengthen the explanatory power of the relational theory both regarding sociology and ethics. In consequence, I propose a Relational Theory of Risk and Danger.
\end{abstract}

Keywords: risk construction, Luhmann, trust, risk conflict, ethics.

\section{Introduction}

In the article "A Relational Theory of Risk" from 2011, Åsa Boholm and Hervé Corvellec propose a theoretical framework for understanding how people consider something a risk. The essence of their theory is that risk emerges in the simultaneity of (1) threatening risk objects, (2) valuable and vulnerable objects at risk, and (3) the relationship between (1) and (2) by the assumption of causal relations between them. This relational theory of risk enables Boholm and Corvellec to cast light on the social risk conflict that arises when people construct risk relationships in mutually exclusive ways. Their theory advises risk managers to investigate the values of opposing groups rather than simply trying to inform them about the risk calculations of experts.

However, the risk management application of the relational theory of risk does not exhaust the potential of Boholm and Corvellec's article; the article also entails two important ethical perspectives. The first ethical perspective concerns the struggle to reject and "exclude" the thing or person that one constructs as a threatening risk object. Although Boholm and 
Corvellec appear mostly descriptive about this dynamic, I will argue that normative questions arise immediately from the struggle to keep others out. The second ethical perspective concerns the ethical consequences of the relational theory's focus on risk. Focusing entirely on risk, I will argue, the theory consolidates the social attribution of harm to endogenous risk rather than exogenous danger, a priority that overburdens modern society with responsibility. ${ }^{1}$ These two crucial ethical features of the relational theory of risk invite further reflection.

Therefore, this article investigates the relational theory of risk and seeks ways to refine it, using an interdisciplinary material. Critical insights from the sociology of risk appear, especially the German systems theorist Niklas Luhmann's considerations of risk, danger, and trust. Ethical and philosophical perspectives will qualify and nuance these sociological insights. As an outcome of these deliberations, the article suggests a "Relational Theory of Risk and Danger" that not only speaks to the ethical implications of the relational theory of risk but also to its ability to explain social risk conflict.

Section 2 offers a brief explanation of the relational theory of risk. Sections 3-5 refine the relational theory of risk. Section 3 argues that a relationship of risk is properly a "relationship of danger" if the person either does not perceive the relationship in advance or does not have any options of mitigating it. This section also discusses the ethical consequences of overlooking the distinction between risk and danger in risk theory. Section 4 discusses the relational theory's ethical claim that risk relationships imply an "exclusion" of the threatening object. Instead, the section argues that a risk relationship places the observer in a decision between trust and distrust, and only distrust results in a struggle of exclusion. Section 5 suggests that when a person constructs a risk-relationship, the distinction between risk and danger poses the question of the origin of the negative consequences, either in the person suffering the harm or in something external. This question is key to the analyzing social risk conflicts. In section 6, I finally present the Relational Theory of Risk and Danger. 


\section{The Relational Theory of Risk}

Let me begin with a hypothetical example that will assist in explaining the relational theory of risk. An Italian tourist guide earns money by informing tourists about the Leaning Tower of Pisa. One day, a tourist asks the tourist guide whether the Leaning Tower of Pisa is earthquake proof. Just short of answering, the tourist guide dwells on the image of an earthquake striking the Tuscan region, powerfully enough to lay the Leaning Tower in ruins. The tourist guide shivers as images of the consequences for her, for Italy, and for the world cultural heritage flash before her eyes.

The relational theory of risk offers a framework within which one can understand the dynamics of such an example. The following compact statement captures the key aspects of the theory:

[Risk results] from situated cognition that establishes a relationship of risk linking two objects, a risk object and an object at risk in a causal and contingent way so that the risk is considered, in some way and under certain circumstances, to threaten the valued object at risk. (Boholm and Corvellec 2011, 176)

The concept of "objects" denotes all phenomena that people can identify as one among other objects, like the driver of a Ford Focus, the Leaning Tower of Pisa, classical music, or democracy. ${ }^{2}$ To identify an object a person has to make use of distinctions (Boholm and Corvellec 2011, 177). For example, the proper name serves sufficiently to identify the Leaning Tower of Pisa among other towers.

The relational theory places an object in either one of two positions, either as "an object at risk" or as a "risk object" (see figure 1). An object can be "at risk" if it meets two requirements. First, a person must ascribe value to it, as the tourist guide ascribes value to the Leaning Tower of Pisa because she makes her living on it, but also because she values its importance as a symbol of her country and for the cultural heritage of the world. Boholm and Corvellec emphasize how ascription of value varies depending on the cultural context and the personal preferences of the 
person. Second, an object is "at risk" only if it is vulnerable to a certain threat, say an earthquake. The Leaning Tower, then, meets both the requirements of value and vulnerability and therefore constitutes an object suitable for being an object at risk.

The threatening earthquake occupies the other side of the risk relationship equation. Boholm and Corvellec define the threatening object as the "risk object." In other words, a risk object is what a person perceives as threatening to the object at risk. The risk object may decrease the value of object at risk or even eliminate the object at risk altogether, like an earthquake may destroy the Leaning Tower. In sum, the definition of the risk object and the object at risk is interdependent. The construction of a risk relationship between a risk object and an object at risk occurs in a person at a certain time; and when it does, both objects are constituted simultaneously.

The person constructing the risk relationship, in Boholm and Corvellec's terminology, constitutes a "situated cognition." 3 The cognitive aspect derives from the way in which the person constructs a risk relationship, namely through a creative imagination. In his or her situated context, the person imagines a certain train of events in which a risk object may causally affect an object at risk so that the value of the object at risk decreases. This imagined train of events constitutes a "risk narrative." 4 Occasioned by a tourist's questions, the Italian tourist guide imagines that an earthquake (the risk object) occurs, strong enough to destabilize the Leaning Tower (the object at risk), whereby the guide has constructed a risk relationship between earthquake and tower.

After this brief summary of the relational theory, which I endorse, the next three sections discuss ways to refine the theory. The first problem concerns those relationships where the valuable and vulnerable object is properly in danger, rather than at risk.

\section{Relationships of Danger}

Solely focusing on the concept of "risk", the relational theory of risk overlooks that humans also find themselves exposed to negative events 
beyond their perception and agency. ${ }^{5}$ In "A Relational Theory of Risk", Boholm and Corvellec suggest—with a reference to Luhmann — that "relationships of risk are bound to action and decisions to act" (Boholm and Corvellec 2011, 181). Luhmann's notion of risk is characterized by a seminal distinction between risk and danger. While a risk is attributed to an agency, a danger is attributed to the external environment. If the reader takes Boholm and Corvellec's reference to Luhmann's theory at face value, their statement implies that when a person has constructed a risk relationship, this person has the agency and responsibility for acting on it, for trying to prevent the risk object. Let me expand this point a bit further by presenting Luhmann's distinction between risk and danger.

In Luhmann, the distinction between risk and danger presupposes the observation that the future is inherently uncertain and insecure (unsicher). The future does not appear to follow from deterministic laws, and even if it did, humans often do not possess enough information about the determinant factors to foresee the future. So, rather than considering risk in distinction to certainty and security, Luhmann seeks to pair the concept of risk with something that also presupposes insecurity. Therefore, Luhmann suggests a distinction between "risk" and "danger." Both risk and danger denote possible harm (Luhmann 1990, 138). But the distinction between them hinges upon their attribution: if the harm derives from an internal decision, the harm is a "risk"; if, in contrast, the harm originates in the external environment, the harm constitutes a "danger" (Luhmann 1990, 148-49). ${ }^{6} \mathrm{~A}$ consequence of Luhmann's distinction is the following: if all relationships between threatening and valuable-vulnerable objects were relationships of risk, as the relational theory of risk would have it, then, the harm is assigned always to the injured party - the victim of the harm - and never to the injured party's external environment.

In view of this observation, this section discusses the conditions of possibility for a risk relationship in distinction from a "danger relationship." In a "danger relationship," the harm does not derive from the injured party itself, but from something in the external environment (3.1-3). The last 
segment (3.4) considers the ethical relevance of signifying some relationships as relationships of danger rather than relationships of risk.

\subsection{Familiarity with the World}

Constructing risk relationships is not the primary human mode of being. Prior to that, human beings find themselves in a state of pre-reflexive familiarity with the world. Even while one constructs a risk relationship, one takes the rest of the world for granted. Humans live with "that attitude, which has no particular frame of reference, of unquestioning security in relation to what is not expressly thought and intended" (Luhmann 1979, 92). Familiarity with the world means expecting the continuity of the world, expecting that the world stays roughly the same. While showing people around, the tourist guide is concerned with capturing the attention of her audience, thus presupposing the continuity of traffic, the presence of the Leaning Tower, etc.

In this state of familiarity with the world, things may occur to a person that this person was not antecedently aware of. In such a situation-prior to the construction of a risk relationship - humans live in danger. This phenomenon can be conceptualized with former US Secretary of Defense Donald Rumsfeld's reference to "unknown unknowns"- harms that we don't even know that we don't know about. Before the terrorist attack on New York 9/11 2001, US military had spent billions of dollars erecting a missile shield anticipating missile attacks from rogue states but had not imagined that civil airplanes could be used as missiles too.

Unknown unknowns are relative to the person's knowledge stand. One person's knowledge is often another person's ignorance. The 9/11 attackers had worked with the narrative that hijacked planes could become a threat to the World Trade Center - to them, this narrative did not constitute a risk relationship — but even so, this narrative still constituted an unknown unknown to the US military. In the relational theory of risk, the subjectivity of the person features centrally: only if a person has constructed the risk relationship — sometimes aided by other people's risk narratives — only then 
does the risk relationship exist for this person. Unknown unknowns, by contrast, constitute dangers par excellence.

\subsection{Vague Risk Objects}

In the relational theory of risk, a risk relationship contains definite risk objects: this dog threatens to bite this baby boy. But human beings may also construct — or better still, sense — risk relationships, where the threatening risk object is vague and undefined. Søren Kierkegaard's influential distinction between fear and anxiety can illuminate what such a vague risk relationship may mean. In Kierkegaard, fear has a definite object, so fear is how one often relates to a well-defined risk relationship: the tourist guide may fear a barking, and potentially biting, stray dog passing by her as she shows around the tourists.

In contrast, an object of anxiety escapes definition; its object is nothingness itself (Kierkegaard 2013, 313). ${ }^{7}$ The mere possibility that something bad could happen in this or that regard may daunt people without enabling them to define the object of their concerns. Before the tourist guide was asked, the presence of the very leaning tower may have installed an anxious insecurity in her. However, as soon as people define the risk object, anxiety turns into fear (Wilkinson 2001, 19-20), but constructing a risk relationship with vague objects makes people anxious.

\subsection{No Options}

Even when a person constructs a definite relationship between a threatening object and a valuable and vulnerable object, this relationship only becomes one of risk if the person has actual options of preventing the risk object or securing the object at risk. A possible harm is a risk only if the potentially injured party has a significant degree of knowledge and agency. If the victim has neither knowledge nor agency, Luhmann's distinction between risk and danger implies that the threatening relationship constitutes a relationship of danger. ${ }^{8}$ 
A genuine risk relationship requires that the observer both constructs the risk relationship and has a real set of alternative options to choose from. When this definition of risk speaks of "options" available to the observer, options should be understood concretely, not necessarily with reference to an abstract free will. Luhmann notes the problem with a society that attributes harm to individuals according to an abstract notion of choice.

To the extent that society imputes decisions and a corresponding mobility, there are no longer any dangers that are strictly externally attributable. People are affected by natural catastrophes, but they could have moved away from the endangered area or taken out insurance. To be exposed to danger is a risk. (Luhmann 1998, 71)

The science-and-religion scholar Niels Henrik Gregersen rightly draws attention to the "considerable degree of arrogance" in the idea that the victims of natural disasters could just have moved (Gregersen 2002, 220). ${ }^{9}$ But I claim that the arrogance lies first of all with the society-or the organization - that places responsibility on the individual rather than on itself or simply on the uncontrollable nature of things.

\subsection{From Danger to Risk, and Back}

The last three sections have shown some requirements for a relationship of risk. A relationship between a threatening and a valuable and vulnerable object is a relationship of risk only if the injured party (1) actually constructs the relationship, (2) constructs the relationship in such a definite way that his or her response goes from anxiety to fear, and (3) has substantial options for mitigating the relationship, through precaution, preemption, preparedness or other anticipatory actions (Anderson 2010, 788). If these requirements are not in place, the relationship is rather one of danger.

Without the aspect of danger, the relational theory of risk comes to follow a problematic trend towards attributing negativity to the injured party. According to Luhmann, increased knowledge and options for the individual person has turned dangers into risks. For example, more 
knowledge about risk factors in medicine turns the danger of disease into a risk of one's own lifestyle (Luhmann 2011, 44, see also Lupton 1999). Before the extensive research into different carcinogens, cancer was a danger; now, many different warnings are in place, among which the most prominent, arguably, is “Don't smoke!” So, getting cancer now largely constitutes a risk. ${ }^{10}$ In general, the increase of knowledge and options has resulted in a general attribution of harm to the injured party rather than the external environment. The relational theory of risk allows that risk objects and objects at risk change place in a battle of definitions (Boholm and Corvellec 2014, 14-16 on the 1996 controversy about Shell sinking the Brent Spar platform). Such definitional contests of "association" and "dissociation" of causal connections between threats and vulnerable valuables also apply to the question of danger or risk, as Boholm and Corvellec's study of a windmill platform has shown (Corvellec and Boholm 2008, 638); but the argument here is that the overall societal increase in knowledge and options results in a general transfer from danger to risk.

Existing risk literature has pointed out that this transfer from danger to risk is problematic because reputational risks, that is, the management of guilt and blame, become more important for the organization than the management of material risks (Power 2004, especially 37-42). But a philosophical perspective also goes into the existential ramifications of this practice. The discrepancy between life-style and norms threatens to overburden the human self-relation concerning the key ethical component of guilt.

Overburdening the human individual with responsibility distorts the human sense of guilt, which plays a vital role in the ethical awareness that underlies human co-existence. The human sense of guilt should correspond to human actual relations of guilt concerning harm done to others. One should feel as guilty as one is. But our sense of guilt can deviate from this correspondence in two ways. ${ }^{11}$ The human sense of guilt can deviate "neurotically" when the overburdening of responsibility results in a too generalized sense of guilt. If an injured party internalizes the all- 
encompassing societal allocation of responsibility to oneself, the injured party succumbs existentially under the weight of his or her guilt. One feels guiltier than one is. But human sense of guilt can also deviate "psychopathically." There may be a point where the neurotic sense of guilt becomes so pervasive that it challenges the person to a protest. Rather than striking a proper balance between human relations of guilt and human sense of guilt, the person protests against the idea of guilt altogether, deeming it irrelevant to his or her existential orientation. Such a protest against the idea of guilt allows the person's healthy sense of guilt to wither away. One feels less guilty than one is. In sum, the societal transfer from danger to risk, which places all responsibility on the injured party, has problematic ethical consequences.

A philosophical approach to this societal situation seeks resources to ease the overburdened human responsibility that results in a distorted sense of guilt. Luhmann's distinction between risk and danger offers such resources by enabling social theorizing to insist on the aspect of danger. Due to the ethical consequences of an exclusive focus on risk, a refined relational theory of risk should be precise about the conditions for considering threatening relationships as relationships of risk. These conditions are knowledge and options. Threatening relationships where the injured party has neither sufficient knowledge nor available options should be constructed as relationships of danger.

\section{Risk Relationships and Trust}

The last section ended with the observation that a relationship between a threatening and a valuable and vulnerable object should be considered one of risk only if a person can imagine the causal connection between the two objects and has available options for mitigating their relationship. But even though the injured party is capable of mitigating the risk relationship, this does not entail that the person should make use of this option, since mitigating a risk relationship entails rejecting and excluding the risk object from one's space of concern. 
This section claims that the rejection and exclusion of the risk object only materializes if the observer chooses to distrust the risk object rather than trusting it. In contrast, Boholm and Corvellec suggest that a risk relationship always motivates the risk manager to "exclude" the risk object.

If designating a risk object is a double act of selection and exclusion, then designating an object at risk is a double act of selection and inclusion. Risk management and governance strive to keep the risk object out and the object at risk in by developing an adequate risk management regime. (Boholm and Corvellec $2011,180)^{12}$

However, I claim, when the person constructing a risk relationship chooses to trust the risk object, the person maintains the risk object in his or her space of concern. Trust includes a risk object, only distrust excludes it. To justify this claim, I draw upon Luhmann's early book on interpersonal trust (and trust in systems), so the following investigation is restricted to human risk objects. ${ }^{13}$

Relationships of risk can arise when one realizes that another person is free to do anything imaginable, even harmful things. When considering the damaging options of another person, one can construct him or her as a risk object within a risk relationship. Such a risk relationship places the constructing person in a position where he or she has to consider whether to trust or distrust the other.

Trust, in Luhmann's terminology, is the expectation that the trustee behaves in concordance with his or her personality. Trust is the generalized expectation that the other will handle his or her freedom, his or her disturbing potential for diverse action, in accordance with the personality that he or she has presented and made socially visible (Luhmann 1979, 39). Trust assumes that the other will behave in accordance with his or her personality, but trust also anticipates that the actions of the other will contribute to a meaningful life, including also the life of the truster. As Luhmann puts it: "One trusts if one assumes that this behaviour [of the other] will fit in meaningfully with one's own pattern of life; one distrusts if 
one reckons that this will not be the case" (Luhmann 1979, 72). While one realizes that the other in fact constitutes a risk object, one can still choose to trust that the other person does not actualize his or her threatening potential but participates in the co-construction of meaningful lives.

Trusting the risk object constitutes a response that includes the risk object rather than excluding it. Only when one chooses to distrust does one exclude the risk object and take action either to pacify the risk object or protecting the object at risk. The risk object is only excluded when the person distrusts the risk object.

The ethical concern with trust and distrust derives from the inherent uncertainty of the choice between them. The choice of trust and distrust cannot be based on any secure foundation; rather, trust and distrust are performative in the sense that they create the reality that they assume. Let me explain this statement. According to Luhmann, any decision about trust depends on an interpretation of the available knowledge and signs. One rarely places trust or distrust in someone without analyzing the context in a search for objective reference points. One bases the trust/distrust-decision on reasons and signs, among other things the personality of the object of trust. But since trust and distrust relate to the infinite potentialities of the future actions of others, one can never completely justify one's decision to trust or not with reference to these signs and reasons. As Luhmann notes, “Trust remains a risky undertaking" (Luhmann 1979, 27). Since neither trust nor distrust can be fully rationalized, to trust or not to trust is finally a decision that has performative consequences. If one trusts, one settles on the signs in favor of trusting and thus constructs the person as someone who can be trusted. If one distrusts, one focuses on the negative signs and the person becomes someone who cannot be trusted.

Luhmann's distinction between trust and distrust enables the observation that Boholm and Corvellec's relational theory of risk focuses only on what happens when a person distrusts. As they argue, constructing a risk relationship — and, I should add, maintaining it into distrust of the risk 
object — involves "designating" one object as dangerous and another object as valuable and vulnerable. Boholm and Corvellec warn,

designating an object as 'dangerous' does not simply entail affixing a label of dangerousness to something that exists already. Designating something as of one kind rather than another is a constitutive act that outlines the object's contours. The emphasis on characteristic traits provides the object with an identity; correspondingly, this emphasis involves downplaying other traits of the object and considering them less significant. (Boholm and Corvellec 2011, 179)

The result of reacting to a risk relationship with distrust in the risk object is that the constructing person excludes the risk object from his or her concerned attention. As the public theologian Miroslav Volf suggests, exclusion of the other destroys the valuable otherness of the other, sometimes by constructing the other as an enemy to be destroyed, sometimes by coercing the other to assimilate to one's own standard (Volf 1996, 67). Both exclusionary options are distrusting attempts to remove the other from its status as a risk object, instead of respecting the freedom of the other.

So, a refined relational theory should add that trust, while respecting the infinite possibility of the other even to do harmful things, expects that the other does not make use of that possibility in the future. Instead, trust relies on the possibility that the mutual life plans could enhance one another. In the context of railway planning, Boholm and Corvellec find that contracts are necessary but finally incomplete ways of controlling contractors. Ultimately, railway planners need a certain amount of trust in their contractors if the planners are to embark on a grand railway project (Boholm and Corvellec 2016, 121).

This insistence that trust plays a significant role in the construction of risk relationships enables a philosophical perspective relating to the difference between trust and distrust. From a philosophical point of view, I will argue, trust is in fact better than distrust. Of course, some situations require a responsible person to distrust, but a philosophy of love would 
argue that the performative consequences of distrust are ethically problematic. Philosopher of religion Claudia Welz suggests, with reference to Søren Kierkegaard, that love of another seeks to avoid a construction of the other as less trustworthy than the other actually is. In fact, love would rather prefer suffering the consequences of a naive trust to overlooking the possibility of good in the other.

Certainly, to be played for a fool hurts the vanity and pride, but it is just as shameful to anticipate evil when good was actually present. The loving person fears to be prejudiced and wrong, so the loving person believes and hopes all [good things from the other]. (Welz 2009, 65, my translation)

Of course, the result of trust sometimes goes well beyond having one's pride prickled, it may result in true suffering, so-again — some situations necessitate distrust.

But the ethical perspective of love encourages the person who constructs the risk relationships to challenge the cultural standards of accepted risk relationships. According to Boholm and Corvellec, the cultural situation constrains what can count as a risk relationship and what cannot. They focus mostly on descriptive standards like "acknowledged natural laws" or "established principles of scientific, discovery, rules of media representation, or the game of social forces" (Boholm and Corvellec 2011, 179). However, culture also provides normative standards with which to select risk relationships. So, even if one's culture would easily accept certain risk narratives and jump to acts of exclusion, the ethical perspective of Welz appeals to the individual that he or she remembers the shame of believing the worst about others and instead considers the trust of love that hopes all good things.

The ethical insights that derive from observing that the constructing person has a choice between trust and distrust make it imperative for a refined relational theory of risk to incorporate Luhmann's distinction between trust and distrust. 


\section{Risk Objects and Danger Objects}

A third and last point concerns the social conflict that can arise around antagonistic constructions of risk relationships when mutual trust has broken down. While the relational theory of risk understands risk conflicts as the result of differing constructions of what counts as risk object and object at risk, this article uses Luhmann's distinction between risk and danger to raise question of the origin of the object that threatens the valuable and vulnerable object.

Boholm and Corvellec analyze a case about a ridge in Southern Sweden, where high ground water pressure fertilizes the soil for agriculture. At one point, the walls of the tunnel started leaking water, which incited conflict. On the one hand, local farmers viewed the high ground water as the object at risk and perceived the tunnel as the risk object because the leakage reduced the valuable ground water. On the other hand, the tunnel builders saw the tunnel as a valued item partly because a tunnel at that place would improve public transportation in the whole region of Southern Sweden, partly because a lot of money had already been poured into the project. For them, the high ground water became the risk object threatening to destroy the whole railroad project (Boholm and Corvellec 2011, 184-85). Thus, the two risk groups constructed their risk relationships in exactly opposite ways. As a result, the two groups wanted opposite policies: lowering the ground water pressure or stopping the tunnel building.

The relational theory offers an analysis of risk constructions, an analysis that aids explaining the logic of antagonistic risk relationships. When people have different constructions of what counts as the risk object and as the object at risk - and when they have chosen to distrust rather than trust-risk conflicts arise. The oppositional risk narratives result in conflicts that can only be solved if both parties are willing to inquire into the values of the other person and find axiological compromises.

But a refined theory of risk can use Niklas Luhmann's distinction between risk and danger to add a significant layer to the explanation of risk conflicts: a refined theory ought to take into account who brought about the 
threatening object. Depending on the point of view of the observer, the same threatening object may be either a risk object or what I would call a "danger object." While the person who has brought about the threatening object would consider it a risk object (the perspective of the tunnel builders), the person who perceives the threatening object as externally generated would see the threatening object as a "danger object" (the perspective of the local farmers).

This difference of perspective, whether the possible harm is selfinduced or imposed by others, whether it is endogenous or exogenous, changes the two parties' assessment of the harm.

\footnotetext{
People for whom the risk behavior of others becomes a danger will evaluate [the threat from the risk behavior] differently than those who make the decision themselves or participate in it. In other words, there are structural occasions for the ongoing reproduction of consternation conflicts. (Luhmann 1990, 163, my translation)
}

This structural difference between the injured party and the decision maker implies that solutions to social risk conflicts cannot merely be concerned with offering full information, as usual risk communication theory suggests (see Boholm 2008, 136). Nor can risk managers solve risk conflicts simply by listening to the values of the conflicting parties, as the relational theory of risk suggests - even though clarification of the key values at stake is integral to any effective risk communication (Boholm and Corvellec 2014, 13). Both of these types of risk management overlook the distinction between the decision maker and the injured party, between risk and danger (Luhmann 1990, 152).

A refined relational theory of risk would argue that risk conflicts are not only about lack of information and axiological differences; they are also about who is responsible for the genesis of the threatening situation. In another article, Boholm utilizes Luhmann's distinction between risk and danger, which enables her to consider the following: "In order for communication about risk to result in mutual understanding [...it requires] a 
transition of decision of power from regulator to stakeholder" (Boholm 2008, 136). Sharing power, engaging more people in the decision making process, is certainly a way to resolve some risk conflicts. Not everyone can participate equally in all decisions (Luhmann 2011, 153), so practices of sharing power cannot ultimately solve risk conflicts. Conflict remains a possibility. But the vulnerability to such conflict may be necessary for proper cooperation. At least, this is the basis for feminist ethicist Sharon Welch, who has argued for what she calls "an ethic of risk."

Welch opposes an "ethic of control" that construes responsibility ${ }^{14}$ as the ability to ensure the implementation of one's goal with certainty (Welch $2000,14)$. This ethic rules in the idea that a responsible risk manager mitigates and manages one's own risk relationship. An ethic of control implies that one has the power to enforce a process according to one's own plans. Welch argues that such an ethic of control is problematic. For, if the implementation process involves other human parties with risk relationships, the concentration of power implied in its concept of responsibility relies on a morally problematic imbalance of power (Welch 2000, 17). Instead, Welch advances an understanding of responsibility that she calls an "ethic of risk." According to this ethic, "[r]esponsible action [means] the creation of a matrix in which further actions are possible, the creation of the conditions of possibility for desired changes" (Welch 2000, 46). Instead of requiring a job done by one individual, responsible action encourages the individual to take risks in creating conditions that can further more actions, also by others and in the future. Sharing power with others equals running the risk that others may influence the process, but sharing power also reduces the possibility of conflict that derives from experiencing harm as exogenous.

The insistence on the aspect of danger is not only relevant for a refined relational theory of risk due to the existential relating to human sense of guilt (see section 3.5), but also in connection with the different assessment of possible harm, whether it derives from oneself or from another party. 


\section{The Relational Theory of Risk and Danger}

In this article, I have argued for three ways in which one could refine the relational theory of risk. This final section describes the resulting contours of the "relational theory of risk and danger" in three brief points.

First, humans are in danger without prior knowledge or available options. Humans are in danger either if they are unaware of the relationship between a threatening and a valuable and vulnerable object or if they do not have any options of mitigating that relationship. If so, a "relationship of danger" exists. This relationship consists of 1) threatening "danger objects," (2) valuable and vulnerable "objects in danger," and (3) the relationship between (1) and (2) that can be established by the cognition of causal relations between (1) and (2) in a person who is unable to mitigate the relationship between (1) and (2), (see figure 2). If and only if, the person constructs the relationship and has options for excluding the object, a risk relationship emerges.

Second, when a person has constructed a risk relationship, he or she has a choice whether to trust or to distrust the risk object. If the person chooses to distrust the risk object, and that is sometimes necessary, the risk object is excluded and combatted either for destruction or assimilation. Conversely, if the person chooses to trust, the risk object remains included, the otherness of the risk object is respected and the person expects that the risk object acts in ways that result in a meaningful mutual life.

Third, some situations in fact undermine the possibility of trust, sometimes because the other person has constructed a mutually exclusive risk relationship. In such a situation, neither factual nor axiological discrepancies exhaust the possible reasons for conflict. The question of who brought about the threatening object plays an important role (see figure 3 ). The relationship is one of risk if the person ascribing value to the vulnerable object has brought about the threatening object (e.g. the perspective of the tunnel builders); if the threatening object derives from something external to the injured party, the relationship is one of danger (e.g. the perspective of 
the local farmers). If the risky behavior of one person becomes the danger of another, the endangered person has legitimate reason to resist and create a conflict even if the factual and axiological disagreements have been overcome. True involvement in the decision making process may help preventing some of that legitimate conflictual potential, but that requires an ethic of risk that dares to be vulnerable.

Along the way, I have highlighted three ethical features of the relational theory of risk and danger. First, observing that some relationships are dangerous opposes the exaggerated focus on individual responsibility for harming others, an opposition that enables humans to relate properly to a central phenomenon of human conviviality, namely guilt. Second, highlighting that a person constructing a risk relationship has a choice of trusting the risk object, especially if the risk object is human, enables humans to oppose a too distrustful culture and include rather than exclude the usual suspects. Third, insisting that people experience exogenous danger objects differently than endogenous risk objects supports the need for sharing power and the need for an ethic of risk rather than an ethic of control. In sum, the relational theory of risk and danger incorporates significant ethical features that the relational theory of risk overlooks.

Further research into refinements of the relational theory of risk could expand the purview beyond relationships of risk and danger to relationships of "chance" and "hope." While relationships of risk and danger deal with human anticipation of future possible harm, humans also anticipate positive futures. The refined relational theory of risk has distinguished risk- and danger relationships according to the endogenous or exogenous attribution of the harm, respectively. Similarly, future interdisciplinary research could investigate relationships of chance and hope according to endogenous and exogenous attribution of good. Developing a theory of relationships of chance and hope would challenge the gloominess of the future that creates and sustains a culture of ambiguous anticipatory action (Anderson 2010).

\section{Acknowledgments}


I acknowledge the Changing Disaster Research Center at the University of Copenhagen for the $\mathrm{PhD}$-scholarship that has enabled the development of this article. I also thank the anonymous reviewer for helpful comments and references.

\section{References}

Anderson, Ben. 2010. "Preemption, Precaution, Preparedness: Anticipatory Action and Future Geographies." Progress in Human Geography 34 (6): 777-98.

Boholm, Åsa. 2008. "The Public Meeting as a Theatre of Dissent: Risk and Hazard in Land Use and Environmental Planning." Journal of Risk Research 11 (1): 119-40.

Boholm, Åsa, and Hervé Corvellec. 2011. "A Relational Theory of Risk." Journal of Risk Research 14 (2): 175-190.

- 2014. "A Relational Theory of Risk: Lessons for Risk Communication." In Effective Risk Communication, edited by Joseph Arvai and Louie Rivers III, 6-22. Earthscan Risk in Society. London New York: Routledge. . 2016. "The Role of Valuation Practices for Risk Identification." In Riskwork: Essays on the Organizational Life of Risk Management, edited by Michael Power, 1 edition, 110-29. New York, NY: Oxford University Press.

Corvellec, Hervé. 2011. "The Narrative Structure of Risk Accounts.” Risk Management 13 (3): 101-21.

Corvellec, Hervé, and Åsa Boholm. 2008. "The Risk/No-Risk Rhetoric of Environmental Impact Assessments (EIA): The Case of Offshore Wind Farms in Sweden." Local Environment 13 (7): 627-40.

Gregersen, Niels H. 2002. "Faith in a World of Risks: A Trinitarian Theology of Risk-Taking." In For All People - Global Theologies in Contexts: Essays in Honor of Viggo Mortensen, edited by Else Marie Wiberg Pedersen, Holger Lam, and Peter Lodberg, 214-33. Grand Rapids, MI.: William B. Eerdmans Publishing Company.

Huber, Wolfgang. 2012. "After Fukushima: The Precautionary Principle Revisited." Verbum et Ecclesia 33 (2): 1-6.

Kierkegaard, Søren. 2013. The Concept of Anxiety: A Simple Psychologically Orienting Deliberation on the Dogmatic Issue of Hereditary Sin. Edited and translated by Reidar Thomte and Albert Anderson. Kierkegaard's Writings 8. Princeton, NJ.: Princeton University Press.

Leer-Salvesen, Paul. 2002. Min skyld. Oslo: Verbum.

Luhmann, Niklas. 1979. Trust and Power: Two Works. Avon: Wiley. . 1990. "Risiko und Gefahr." In Konstruktivistische Perspektiven: Soziologische Aufklärung V, 131-69. Opladen: Westdeutscher Verlag. 
1998. Observations on Modernity. Writing Science. Stanford, CA.: Stanford University Press.

2011. Risk: A Sociological Theory. Meuchen, DEU: Walter de

Gruyter.

Lupton, Deborah. 1999. Risk. Key Ideas. London: Routledge.

Power, Michael. 2004. The Risk Management of Everything: Rethinking the Politics of Uncertainty. London: Demos.

Volf, Miroslav. 1996. Exclusion and Embrace: A Theological Exploration of Identity, Otherness, and Reconciliation. Nashville, TN.: Abingdon Press.

Welch, Sharon. 2000. A Feminist Ethic of Risk. Second, Revised edition. Minneapolis, MN: Fortress Press.

Welz, Claudia. 2009. Vertrauen und Versuchung. Tübingen: Mohr Siebeck. Wilkinson, Iain. 2001. Anxiety in a Risk Society. Health, Risk and Society. London: Routledge.

${ }^{1}$ Ethicist Wolfgang Huber distinguishes the "retrospective responsibility" of taking responsibility for one's action in the past from the "prospective responsibility" of taking responsible action for the future (Huber 2012, 1). The responsibility here is retrospective.

${ }^{2}$ Boholm and Corvellec suggest "physical, cultural, or social artifacts," but these three categories do not exhaust the realm of objects available here; e.g. the personal zone of intimacy could be at risk and therefore expands the list.

${ }^{3}$ Sometimes, the relational theory also uses the term "observer," which also Luhmann prefers.

${ }^{4}$ Elsewhere Corvellec offers insights into how individual construction of risk narratives can be inspired by signs of risk - say, warning signs in public transportation - that are narrated by administrative entities (Corvellec 2011, 106-12).

${ }^{5}$ See footnote 8 for a qualification of this statement.

${ }^{6}$ The general purview of Luhmann's theory could suggest that such attribution is an exclusively social process. But sometimes Luhmann speaks of the distinction between risk and danger more phenomenologically, in the sense that risk requires the person to have knowledge about certain alternatives to choose between. Since the purpose here is the conversation with the cognitivist relational theory of risk, I allow the phenomenological interpretation to dominate this article.

${ }^{7}$ For Kierkegaard, the object of anxiety is oneself, or specifically one's manifold possibilities of relating to future realities. The object is “freedom's actuality as the possibility of possibility" (Kierkegaard 2013,313). This means first, that not only the possibility of something, but the sheer possibility of possibility is what is anxiety provoking. Second, Kierkegaard insists that a person has to learn to be properly anxious (Kierkegaard 2013, 421) because proper anxiety reveals one's self as freedom and responsibility. Third, Kierkegaard emphasizes that anxiety, properly speaking, comes from 
within, not from without, although people usually seek the root of anxiety outside themselves (Kierkegaard 2013, 421). Here, I extend Kierkegaard's analysis of anxiety (Angst) to encompass also a sense of the anxiety that derives from indefiniteness outside of the human subjectivity.

${ }^{8}$ In a later article, Boholm and Corvellec find that risk workers in a railway project have an acute sense not only of what I, with Rumsfeld, call unknown unknowns but also that a whole array of identified risk relationships are beyond their control (Boholm and Corvellec 2016, 13-15). However, these risk workers do have one specific sense of control or agency, which means that their threats still constitute risks: these risk workers can recommend that the railway project be brought to a halt. This situation creates a fascinating dialectic. One the one hand, embarking on a grand project, like building a new railway, means that all threats constitute risks. Management of those risks entails decisions that are equivalent to second-order risk-taking. One the other hand, once the project has begun, it constitutes a reality, within which employees find themselves exposed to unforeseen or unmanageable events, say extreme storms, that would threaten life, project or not. These relationships, then, still constitute relationships of danger.

${ }^{9}$ Whether Luhmann defends this view or is being sarcastic is unclear.

${ }^{10}$ Exemplified with public warning signs, Corvellec discusses how public risk accounts applied by the state places responsibility on the individual person: "risk accounts also engage the responsibility of narrates to do what they reasonably can now that they know what may happen," (Corvellec 2011, 114).

${ }^{11}$ This section builds on the insightful observations of the ethicist Paul Leer-Salvesen 2002, $12-35$.

${ }^{12}$ Elsewhere Corvellec states that "Risk accounts evoke threats, threats evoke fear and fear evokes dangerous Others" (Corvellec 2011, 116). I claim that trust can break this chain of causality either before threats elicit fear or before fear creates dangerous Others.

${ }^{13}$ I should suspect that the results could be generalized also to non-human risk objects. In a qualified sense, trust can also be given to things, say a tree: If a tree looks sturdy, a person will be more inclined to climb it; however, we can hardly speak of the tree breaking the climber's trust. If a branch looks thin and a climber steps onto it anyway, the climber may be humiliated because he or she has trusted too much. Yet, the ethical priority to trust, which I consider at the end of section 4, does not apply to trust in non-human things.

${ }^{14}$ Prospective responsibility (see note 1 ). 